agement and workers : in short, that the attempt to associate trade unions with management is mistaken. If by frank disclosure of information and encouraging a sense of participation in the work of the firm, management could destroy the men's traditional attitude to productivity and replace it by confidence in the fairness, honesty and decency of management, productivity is more likely to be promoted than by a direct attack through joint collaboration.

The clash between individualism and totalitarianism inherent in the present situation cannot be disregarded. It may well frustrate efforts to increase productivity, like the attitude discussed by Mr. Scott, unless, side by side with the scientific study of productivity and the educational work being attempted by the Anglo-American Productivity Council, to which the Parliamentary and Scientific Committee, in arranging this discussion and publishing so promptly this summary, has now lent its powerful support, there is an attempt by both sides to think out a new industrial philosophy in the light of the failures of the past thirty years. Over that period there has been, as Mr. G. M. Young recently observed, a revolution in our thought about the State. It is apparent in our attitude to such matters as the direction of labour, State control, and delegated legislation.

These are issues that touch everyone, scientific and professional men not less than their fellows. They must think out afresh the functions of their professional institutions in the new age, and the conditions under which their specialized service can be most freely and effectively given. One of the merits of this problem of productivity is that it makes plain how wide the area of co-operation and discussion must be. It offers indeed an outstanding opportunity for engaging the interest and providing a field of useful and productive work for those best qualified to participate, and promises to widen the area of well-informed discussion which such factors as party organization, the vast size of a modern electorate and the technical intricacies of modern administration tend to contract.

\section{THEORY OF ATOMIC COLLISIONS}

\section{The Theory of Atomic Collisions}

By N. F. Mott and H. S. W. Massey. (International Series of Monographs on Physics.) Second edition. Pp. $x v+388$. (Oxford : Clarendon Press ; London : Oxford University Press, 1949.) 35s. net.

THE first edition of Mott and Massey's book published in 1933 has become a classic. One evidence for this is that no other book on this subject has appeared. The new edition fulfils the high expectations of the users of the old. It has grown by about one-third in size, and the authors must be congratulated on the wise choice of the added material, as well as on their restraint in not letting the volume grow any more in spite of the large amount of new material available.

With the direction that physics has been taking during the last seventeen years, it was obvious that the main emphasis in the new material had to be on the extension of the theory to relativistic energics and on its application to nuclear collisions. A whole new chapter on nuclear collision phenomena has bcen added. In this chapter the emphasis is properly on the collision aspect, as distinguished from a detailed discussion of the problems of nuclear forces. However, many of the interesting experimental results on the spacing and the width of resonance-levels formed in neutron as well as proton scattering are listed. Sample experimental curves on resonances are given. Emphasis is laid on the theory of the compound nucleus, on scattering of ncutrons by molecules and on magnetic scattering of neutrons.

An especially good feature of the new edition is that the theoretical methods applicable to nuclear collisions are presented, together with the general theory of atomic collisions. Thus in Chapter 8, which treats the general theory of atomic collisions, the "method of the collision complex" (compound nucleus) is discussed in detail and its range of applicability compared with that of other methods. Chapter 8 has generally been improved and clarified. Similarly, in Chapter 2, explicit calculations of the scattering by various special potentials have been added with a viow to the application to nuclear phenomena; a discussion of the dispersion formula for the one-body problem is included. In the chapter on Coulomb scattering, the important radial Coulomb wave functions are discussed in more detail, and the penetrability of the potential barrier has been added.

Next to nuclear effects, the relativistic effects have received most of the additional space. Thus in Chapter 4 the relativistic scattering by a centre of force has bcen expanded and comparison with experiment included. It is gratifying to see that the effect of spin polarization on the double scattering, first predicted by Mott, now agroes with experiment. Adequate discussions are given of the properties of positrons, such as pair production and the differences in the scattering of positrons and electrons.

In the more 'classical' parts of the theory, some sections have been shortened. For example, nobody will much regret the omission of the chapter on the collision of electrons with molecules. Some sections have been much improved, such as the one on exchange effects in scettering of slow electrons, where now agreement with experiment has been achieved, at least for helium. The theory of resonance effects on collisions between atoms has been made more quantitative and at the same time abbreviated. On the other hand, it seems remarkable that the section on the Ramsauer effect has remained unchanged, indicating that apparently no further work has been done on this important subject.

Some slight omissions may be recorded. There is only a very brief reference to 'shadow scattering' and none at all to its importance for nuclear scattering. The reference to the semi-empirical results on the stopping power of matter for fast particles is also extremely brief. The reader might expect a, more thorough treatment of the influence of rediative forces on the scattering by a potential and of the importance of this problem in the recent development of quantum electrodynamics. Apart from these minor points, the selection of material is admirable, not only of that which is included, but also of the topics which are left out or treated briefly.

There is no doubt that this book, like its first edition, will be a necessity for students of quantum theory as well as for many experimental physicists. Hans A. BeTHe 